\section{Can we afford to exercise, given current injury rates?}

\section{R J Shephard}

\section{Fatalities could be reduced through application of our current knowledge}

A ack of adequate and regular physical activity is now recognised as a major factor contributing to many forms of chronic disease, ${ }^{1-3}$ and public health agencies around the world are eager to encourage the general population to become more active..$^{4-6}$ However, papers such as those of Conn and associates, ${ }^{7}$ and repeated surveys from various countries, including Britain, Denmark, ${ }^{9} \quad$ France, ${ }^{10}$ Finland, ${ }^{11}$ Germany, $^{12}$ South Africa, ${ }^{13}$ and the US ${ }^{14}$ note an important social and economic toll from injuries among current exercisers. Some authors have suggested that the incidence of such adverse consequences could be sufficient to counter both health and economic arguments for the advocacy of exercise, ${ }^{15}$ whereas others have considered these injuries an inevitable consequence of participation in health giving exercise. ${ }^{1617} \mathrm{~A}$ journal such as Injury Prevention can hardly accept the position that such events are unavoidable "accidents". Nevertheless, it seems appropriate to question both the magnitude of the problem and the ability to generalise the findings, while suggesting appropriate preventive measures.

As Conn and associates point out, the conclusions that can be drawn from a given survey are limited by problems of recall and seasonal effects. ${ }^{7}$ When attempting to generalise conclusions to other countries, we must add issues associated with differences in legislation, environmental conditions, and the popularity of various sports. For instance, in some countries the wearing of protective equipment may be mandatory, limb injuries in field sports may be increased by frozen playing surfaces, or a given type of activity may result in few injuries because most young men do not play this particular sport.

There is great difficulty in assessing the severity of injuries from survey data, even within a specific country. There can be little argument in the event of a fatality, but it is much less certain that "one or more days" of absence from school or work $^{7}$ implies a severe injury. The true explanation of a day spent within the confines of the medical system could lie in such current issues as a litigious society, the practice of defensive medicine, and time lost through the poor organisation of health services.

Many reports such as those of Conn and associates ${ }^{7}$ also lack a denominator expressing the extent of exposure to various types of activity. Those concerned with injury prevention need detailed information concerning each patient's body build, physical fitness, typical level of competition, cumulative hours of exposure to a given sport, and immediate environmental conditions as a prelude to deciding which combinations of athletic pursuit, intensity, and environment are potentially dangerous. ${ }^{18} 19$ Differences in exposure to specific sports could explain some of the apparent ethnic differences in susceptibility to injury in the US. ${ }^{7}$ The main cause of the striking age and gender gradients in injury statistics probably lies in a combination of lack of experience, testosterone-mediated aggressiveness and inappropriate social conditioning among adolescent males, but it is again likely that such influences are tempered by age and gender related differences in the intensity and duration of exposure to dangerous sports.

Even more importantly, current assessments of the risk of a sport induced injury are based on data from individuals who have themselves chosen to adopt specific patterns of exercise. Such assessments are unlikely to reflect the risk of adverse health effects and associated medical costs among those who might be persuaded to increase their current level of physical activity through government propaganda. This point is well illustrated by a quasiexperimental study that compared health outcomes between an office that instituted a moderate aerobic fitness programme for their employees, and a matched control office where there was no such initiative. ${ }^{20}$ Employees at the company where the fitness programme was introduced showed no increase in Ontario Health Insurance Plan billings for either orthopedic or cardiovascular services, either relative to their personal experience during the previous year, or relative to billings for employees of the control company during the same year. Indeed, the introduction of the fitness programme appeared to reduce the immediate medical costs of the experimental sample by the equivalent of about three physician visits and a half day of hospital care per employee year. ${ }^{20}$

Most sports injury statistics are undoubtedly inflated by the problem of self selection. Lesions are most likely in boys and young men. Many in this group enjoy taking risks, and danger is a major factor attracting them to dangerous and extreme forms of sport. The discouraging reality is that even if we were to eliminate the risks associated with such forms of sport, it is likely that the participants would then choose to gain an "adrenaline rush" by adopting some other hazardous type of activity, such as driving on an expressway at an aggressive $200 \mathrm{~km} / \mathrm{h}$.

This is not to deny our responsibility to implement simple methods of reducing the risk of exercise induced accidents. A first step must be to develop adequate statistics, so that we can rank the various potential activities in terms of risk; then we can encourage the adoption of those pursuits where the ratio of health benefit to risk is high. Brisk walking is a popular, low risk choice among the general population, ${ }^{21}$ and at least for the older half of our citizens, it confers many of the preventive medical dividends promised by riskier forms of physical activity. ${ }^{22}$ The attention of governments is now turning from the provision of costly sports facilities to encouraging the incorporation of such simple types of regular physical activity into normal daily life-the "active living" option. ${ }^{23}$ Cycling to and from school or work is potentially a valuable component of active living, but in most communities there is a need to enhance the safety of such transportation through the provision of dedicated, attractive, and well lit walkways and cycle paths. The alarming toll of head injuries among cyclists could also be almost halved if other legislatures were to follow the initiative of some Canadian provinces by making the wearing of cycle helmets compulsory. ${ }^{24}$

Some people will continue to find their motivation to an active lifestyle through the excitement of competitive sport, or the pursuit of individually challenging objectives. The risk to such individuals could still be substantially reduced through a careful matching of the exerciser's abilities with that of the competitor or the environment, the refinement and enforcing of rules of fair play, good maintenance of grounds, and insistence on the wearing of appropriate protective equipment. We will continue to see some injuries and even fatalities among walkers, cyclists, football players and rock climbers alike, but we must be disturbed when the current incidence of fatalities could be greatly reduced 
through a simple application of our current knowledge.

Injury Prevention 2003;9:99-100

\section{Author's affiliation}

R J Shephard, Faculty of Physical Education and Health and Department of Public Health Sciences, Faculty of Medicine, University of Toronto, Toronto, Ontario, Canada

Correspondence to: Professor Roy Shephard, PO Box 521, Brackendale, BC VON 1HO, Canada; royjshep@shaw.ca

\section{REFERENCES}

Kesaniemi YA, Danforth E, Jensen MD, et al. Dose-response issues concerning physical activity and health: an evidence-based symposium. Med Sci Sports Exerc 2001;33(suppl 6):S351-8

2 Shephard RJ. Aerobic fitness and health. Champaign, IL: Human Kinetics Publishers, 1994.

3 US Department of Health and Human Services. Physical activity and health: a report of the surgeon general. Atlanta, GA: US Department of Health and Human Services, Centers for Disease Control and Prevention, National Center for Chronic Disease Prevention and Health Promotion, 1996.

4 Shephard RJ. Whistler 2001: a Health Canada/CDC conference on "communicating physical activity and health messages: science into practice". Am J Prev Med 2001;23:221-5.
5 Task Force on Community Preventive Services. Recommendations to increase physical activity in communities. Am J Prev Med 2002;22(4S):67-72.

6 US Department of Health and Human Services. Healthy people 2010. 2nd Ed. Washington, DC: US Department of Health and Human Services, Public Health Services (available from http://www.health.gov/ healthypeople, 2000)

7 Conn JM, Annest JL, Gilchrist J. Sports and recreation related injury episodes in the US population. Inj Prev 2003;9:117-23.

8 Williams JM, Wright $P$, Currie CE, et al. Sports related injuries in Scottish adolescents aged 11-15. Br J Sports Med 1998; 32:291-6

9 Sorensen L, Larsen SE, Rock ND. Sports injuries in school-aged children. A study of traumatologic and socioeconomic outcome. Scand J Med Sci Sports 1998;8:52-6.

10 Benamghar L, Chau N, Saunier-Aptel E, et al. [Accidents among students in professiona or technological schools in Lorraine] (French). Revue d'Epidémiologie et de Santé Publique 1998;46:5-13.

11 Sandelin J, Kiviluoto O, Santavirta S, et al. Outcome of sports injuries treated in a casualty department. Br J Sports Med 1985; 19:103-6

12 Oberthaler G, Primavesi C, Niederwieser B et al. [Snowboarding accidents 1991 to 1994-an analysis] (German). Sportverletzung Sportschaden 1995: 9: 118-22.

13 Nel D, Smit PJ, Stoker DJ. [The influence of sports injuries on sport participation and work] (Afrikaans). S Afr Med J 1979;55:426-8.
14 US Consumer Safety Product Commission. Baby boomer sport injuries. Washington, DC US Consumer Product Safety Commission, 2000.

15 Shephard RJ. Economic benefits of enhanced fitness. Champaign, IL: Human Kinetics, 1986.

16 Sahlin Y. Sports accidents in childhood. Br J Sports Med 1990;24:40-4.

17 Bijur PE, Trumble A, Harel Y, et al. Sports and recreational injuries in US children and adolescents. Arch Pediatr Adolesc Med 1995:149:1009-16.

18 de Loës $M$. Exposure data. Why are they needed? Sports Med 1997;24:172-5.

19 MacIntosh D, Skrien T, Shephard RJ. Physical activity and injury. A study of sports injuries at the University of Toronto, 1951-1968. J Sports Med Phys Fitness 1972; 12:224-37.

20 Shephard RJ, Corey P, Renzland P, et al. The influence of an employee fitness and lifestyle modification program upon medical care costs. Can J Public Health 1982;73:259-63.

21 Shephard RJ. Fitness of a nation: lessons from the Canada fitness survey. Basel: $\mathrm{S}$ Karger, 1986.

22 Shephard RJ. What is the optimal type of physical activity to enhance health? Br J Sports Med 1997;31:277-84.

23 Anonymous. Summit on promoting healthy eating and active living: developing a framework for progress. Washington, $D C$ April 25-26, 2000. Nutr Rev 2001;59/3 pt 2):S1-74.

24 Macpherson AK, To TM, Macarthur C, et al. Impact of mandatory helmet legislation on bicycle-related head injuries in children $-a$ population-based study. Pediatrics 2002;110:e60 (abst).

\section{Sports and recreational injury: the hidden cost of a healthy lifestyle}

\section{S W Marshall, K M Guskiewicz}

More exercise will mean less obesity related disease, but exercise related injuries may negate the gain

S port and recreational physical activity is an integral part of our society and participation in recreational physical activity is widely promoted as part of a healthy lifestyle. However, recent studies, such as the paper by Conn et al in this issue of Injury Prevention, point to the significant, and largely underresearched, injury problem associated with sports and recreational injury. ${ }^{1}$ In this guest editorial, we review the evidence for and against increasing the level of physical activity in the general population in developed counties. We also suggest specific collaborations important for controlling sports and recreational injury and for developing future recommendations on physical activity.

Physical inactivity and obesity are a growing problem throughout the developed world. ${ }^{2}$ Increasing affluence has facilitated the consumption of a high energy, high fat diet. ${ }^{23}$ But as food portion sizes have grown, ${ }^{4}$ so too have our waistlines. ${ }^{5}$ Levels of work related physical activity have dropped with the advent of service-orientated economies in developed countries; concurrently, the time available for recreational physical activity has diminished. ${ }^{36}$ Nearly $75 \%$ of US adults report they are not regularly active or are inactive during leisure time. $^{7}$ In addition, the transportation infrastructure in developed countries increasingly discourages walking or cycling in favor of using a motor vehicle. ${ }^{8}$

As a result of reduced physical activity, diabetes and other obesity related diseases have increased. ${ }^{2910}$ Of great concern is the fact that participation in physical education programs by US children and adolescents is low (only $21 \%$ of US adolescents participate in daily school based physical activity programs) and declining, while the prevalence of overweight in this age group is increasing..$^{71-13}$ In part, this is because the leisure time activities pursued in developed counties are increasingly sedentary. Enormous growth in the market for home video/DVD, electronic games, and computers has meant profits for manufacturers and retailers but may mean massive future costs for public health in terms of obesity related disease.

In response, the US Surgeon General issued a call to action in $1996 .{ }^{14}$ A expert panel reviewed the evidence on the protective effects of physical activity in terms of prevention of obesity, cardiovascular disease, colon cancer, diabetes, poor mental health, and musculoskeletal degeneration. It was concluded that, while long duration and/or high intensity exercise conferred the greatest benefits, significant health gains could be achieved through a sequence of short episodes of moderate activity (brisk walking or climbing stairs) spread throughout the day. The recommendation was for each adult to participate in at least 30 minutes of moderate activity per day; this activity could be accumulated in a series of short episodes (say, three sets of 10 minute walks). ${ }^{15}$ The subsequent implementation of this recommendation has been the focus of numerous public health campaigns and much research effort. 
But a hidden danger lurks beneath the surface of the Surgeon General's recommendation, and that danger is sports and recreational injury. ${ }^{14}{ }^{16}$ An increased risk of injury was identified in the Surgeon General's report as the major negative consequence of increasing the level of physical activity in the population. The authors of the report suggested that these injuries could be prevented in sedentary individuals by "gradually working up to a desired level of activity". ${ }^{13}$ However, this suggestion is not supported by the epidemiology of sports and recreational injury. Sports and recreational injuries arise in a wide diversity of activities and occur to persons at all levels of fitness and conditioning. In fact, the evidence linking physical fitness and prevention of sports injury is slight, ${ }^{17}$ and the same is true of warm-up and stretching programs. ${ }^{18}$ By far the biggest determinant of injury risk in sports and recreational injury is the nature of the activity itself, with contact sports carrying the greatest risk of injury. ${ }^{19}{ }^{20}$ Personal history of injury also has an important role, especially in the young athlete. ${ }^{21}$ Given the above, it would have been useful if the authors of the Surgeon General's report could have made specific recommendations about those physical activities which provide maximal cardioprotective benefits while minimizing the risk of injury. ${ }^{16}$

In fairness to the Surgeon General's office, the descriptive epidemiology of sports injury in the US remained an undeveloped area throughout much of the 1990s. Fortunately, three recent reports from the Centers for Disease Control and Prevention have changed that. ${ }^{122} 23$ The most recent of these reports appears in this issue of Injury Prevention. ${ }^{1}$ As a result of this work, the scope of sports and recreational injury in the US has been documented in much greater detail than was possible in previous reports. ${ }^{19} 20$

Findings from this paper underscore the enormous magnitude of the problem of sports and recreational injury. ${ }^{1}$ Using data from the National Health Interview Survey, an annual face-to-face survey of over 37000 households in the US, the authors estimate that there are 26 sports and recreational injury episodes per 1000 persons per year; this rate exceeds the rate for transportation related injury. Obviously there are a marked differences in severity between sports and recreational injuries and transportation injuries, however, $20 \%$ of schoolchildren are absent from school at least one day a year due to sports injuries, and $28 \%$ of working adults lost at least one day a year from work due to sports injuries. Perhaps the most staggering statistic is that for those persons ages 5 to 24 years, sports injuries account for one out of every five injury episodes. ${ }^{1}$
Data such as these call into question the wisdom, in public health terms, of attempting to increase in a broad based manner the level of physical activity in the population. There is a urgent need for specific guidance as to which physical activities confer the greatest health benefits in terms of preventing chronic disease, while minimizing the injury risks. Public health recommendations need to address the specific mix of mild, moderate, and vigorous physical activity not only in terms of chronic disease prevention and treatment, but also in terms of management of the risk of injury. ${ }^{16}$

One of the first steps in identifying issues of public health concern is the gathering of incidence statistics. From an injury control perspective, the problem of sports and recreational injury has gone undocumented for far too long. This is in part due to the fact these injuries tend to be of lower severity. As a result, much of the burden of these injuries has fallen outside the scope of standard data collection systems for fatal and hospitalized injuries. It is also due in part to deficiencies in previous coding systems used to categorize injury, such as International Classification of Diseases, ninth revision, clinical modification (ICD-9$\mathrm{CM})$, which were unable to comprehensively classify sports injuries. Finally, it must be admitted that social dynamics have also played a part; public health professionals have tended not to engage intellectually and socially with their colleagues in exercise and sports science, and vice versa.

What can be done to make sports and recreational activity safer? Protective equipment interventions are one option; in the sports of recreational baseball and softball, safety bases, softer balls, and protective faceguards have all been shown to be effective and are widely adopted. ${ }^{24-26}$ Rule changes also have great potential; the rule changes and player education programs introduced into North American football in the 1970s reduced the incidence of catastrophic injury in that sport from 36 per annum to zero. ${ }^{27}$ More problematic are nebulous, ill defined injuries such as concussion, ${ }^{28}$ or those due to intrinsic forces, such as rupture of the anterior cruciate ligament. ${ }^{29} 30$

An important attribute of analytic epidemiologic studies in sports and recreational injury is the use of the prospective cohort design. This study design has great applicability to the study of sports and recreational injury because cohorts can be assembled and data on putative risk factors obtained at the start of the sports season..$^{31}$ Athletes can then followed over the course of the season and injuries prospectively identified by their health care providers. The time between acquisition of risk factor data and ascertainment of injuries is typically short-weeks or months, as opposed to the years or decades common in occupational or environmental epidemiology. Cohort sizes can be quite modest (hundreds rather than thousands) because sufficient injuries typically present during only a few seasons of follow up. Acquisition of accurate data on participation in sports (so-called "exposure" data) is critical to success of these studies. ${ }^{32}$ Methodologic research on the most efficient techniques for obtaining participation or exposure data is required.

From the prevention standpoint, the sports injury community is notable for the presence of a group of medical professionals known as certified athletic trainers (ATCs). ATCs specialize in the prevention, assessment, treatment, and rehabilitation of injuries and illnesses that occur to those who are physically active. Although the traditional focus of the athletic training profession has been on organized athletics, there is increasing interest in all those who are physically active, including leisure time (recreational) athletes. The National Athletic Trainers' Association (NATA; www.nata.org) represents the over 30000 members of the athletic training profession and publishes the Journal of Athletic Training, a peer reviewed journal that welcomes papers on epidemiology and prevention. The NATA is actively seeking to reach out to injury control professionals and to that end has formed a partnership with the Injury Control and Emergency Health Services Section of the American Public Health Association. Apart being a excellent mechanism for the dissemination of prevention messages, ATCs are also frequently involved in research studies which involve primary collection of injury data. Data collection in one of the largest and longest lived injury surveillance systems in the world, the National Collegiate Athletic Association's Injury Surveillance System, is largely supported through the volunteer work of ATCs.

Sport and recreational physical activity is an integral and vital component of our society. Increasing the level of physical activity in children and adults is a pressing public health concern; however, the injuries resulting from sports and recreational activities are also a grave public health concern. For the US, we now have a clearer picture of those injuries than ever before. ${ }^{122}{ }^{23}$ The burden of responsibility now rests on the shoulders of the injury control professionals to partner with sports medicine professionals and exercise science researchers in order to develop physical activity guidelines that minimize the risk of injury in sports and recreational activities, while maximizing the public health gain from prevention of obesity and other inactivity related disease.

Injury Prevention 2003;9:100-102 
$\ldots \ldots \ldots$

\section{Authors' affiliations}

S W Marshall, Department of Epidemiology, Department of Orthopedics, and Injury Prevention Research Center, University of North Carolina at Chapel Hill, USA

K M Guskiewicz, Department of Exercise and Sports Science, Department of Orthopedics, and Injury Prevention Research Center, University of North Carolina at Chapel Hill, USA

Correspondence to: Dr Marshall; smarshall@unc.edu

\section{REFERENCES}

1 Conn JM, Annest JL, Gilchrist J. Sports and recreation related injury episodes in the US population. Inj Prev 2003;9:1 17-23.

2 World Health Organization. Obesity: preventing and managing the global epidemic. WHO Technical Report Series, No 894. Geneva, Switzerland: World Health Organization, 1998-3.

3 Bouchard C, Blair SN. Introductory comments to the consensus conference on physical activity and obesity. Med Sci Sports Exerc 1999:31:S498-501.

4 Nielsen SJ, Popkin BM. Patterns and trends in food portion sizes, 1977-1998. JAMA 2003;289:450-3.

5 National Institutes for Health Identification, evaluation, and treatment of overweight and obesity in adults. $\mathrm{NIH}$ Publication Number 00-4084. Washington DC: The National Heart, Lung, and Blood Institute and the North American Association for the Study of Obesity, 2000: 13.

6 Haskell WL. Physical activity, sport, and health: toward the next century. Res $Q$ Exerc Sport 1996;67(suppl):37-47.

7 Pratt M. Macera CA, Blanton C. Levels of physical activity and inactivity in children and adults in the United States: current evidence and research issues. Med Sci Sports Exerc 1999;31:S526-33.

8 Frumkin H. Urban sprawl and public health. Public Health Rep 2002;117:201-17.

9 Jebb SA, Moore MS. Contribution of a sedentary lifestyle and inactivity to the etiology of overweight and obesity: current evidence and research issues. Med Sci Sports Exerc 1999:31:S534-41.

10 Saudek CD. Progress and promise of diabetes research. JAMA 2002;287:2582-3.

11 Troiano RP, Flegal KM, Kuczmarski RJ, et al. Overweight prevalence and trends for children and adolescents. The National Health and Nutrition Examination Surveys, 1963 to 1991. Arch Pediatr Adolesc Med 1995:149:1085-91.

12 Gordon-Larsen P, McMurray RG, Popkin BM. Adolescent physical activity and inactivity vary by ethnicity: the National Longitudinal Study of Adolescent Health. J Pediatr 1999; 135:301-6.

13 Gordon-Larsen P, McMurrray RG, Popkin BM. Determinants of adolescent physical and inactivity patterns. Pediatrics 2000-105:e83.

14 US Department of Health and Human Services. Physical activity and health: a report of the surgeon general. Atlanta, GA: US Department of Health and Human Services, Centers for Disease Control and Prevention, National Center for Chronic Disease Prevention and Health Promotion 1996:3-8:142-4.

15 Pate RR, Pratt M, Blair SN, et al. Physical activity and public health: a recommendation from the Centers for Disease Control and Prevention and the American College of Sports Medicine. JAMA 1995;273:402-7.

16 Pugh CB, Waller AE, Marshall SW. Physical activity and public health (letter). JAMA 1995;274:533.

17 Quarrie KL, Alsop JC, Waller AE, et al. A prospective cohort study of risk factors for injury in Rugby Union football. Br J Sports Med 2001;35:157-66.

18 Bixler B, Jones RL. High school football injuries: effects of a post-halftime warm-up and stretching routine. Fam Pract Res J 1992:2:131-9.

19 Baker SP, O'Neill B, Ginsburg M, et al. The injury fact book. 2nd Ed. New York, NY: Oxford University Press, 1992: 89-99.

20 Kraus JF, Conroy C. Mortality and morbidity from injuries in sports and recreation. Annu Rev Public Health 1984;5: 163-92.

21 Kucera K. The NCYSA classic injury study: injury history of the traveling youth player. A paper submitted in partial fulfillment of the of the requirements for the degree of Master of Public Health. Chapel Hill, NC: University of North Carolina, 2002: 1-2.

22 Burt CW, Overpeck M. Emergency visits for sports-related injuries. Ann Emerg Med 2001;37:301-8.

23 Centers for Disease Control and Prevention. Nonfatal sports- and recreation-related injuries treated in emergency departments, United States, July 2000-June 2001. MMWR Morb Mortal Wkly Rep 2002;51:736-40.

24 Janda DH, Woitys EM, Hankin FM, et al. Softball sliding injuries: a prospective study comparing standard and modified bases. JAMA 1988;259: 1848-50.

25 Danis RP, Hu K, Bell M. Acceptability of baseball face guards and reduction of oculofacial injury in receptive youth league players. Inj Prev 2000;6:232-4

26 Marshall SW, Mueller FO, Kirby DT, et al. Evaluation of safety balls and face guards to prevent injury in youth baseball. JAMA 2003;289:568-74.

27 Mueller FO, Cantu RC, Van Camp SP. Catastrophic injuries in high school and college sports. Human Kinetics Sport Science Monograph Series Volume 8. Champaign, IL: Human Kinetics, 1996: 42-7.

28 Guskiewicz KM, Weaver NL, Padua DA, et al. Epidemiology of concussion in collegiate and high school football players. Am J Sports Med 2000;28:643-50.

29 Kirkendall DT, Garrett WE. The ACL enigma: injury mechanisms and prevention. Clin Orthop 2000;372:64-8.

30 Griffin L, Agel J, Albohm M, et al. Noncontact anterior cruciate ligament injuries: risk factors and prevention strategies. J Am Acad Orthop Surg 2000;8:141-50.

31 Walter SD, Hart LE. Application of epidemiological methodology to sports and exercise science research. Exerc Sport Sci Rev 1990; 18:417-48

32 Phillips LH. Sports injury incidence. Br J Sports Med 2000;34:133-6. 